\title{
THE INTERNATIONAL GPS SERVICE FOR GEODYNAMICS (IGS) AND THE TERRESTRIAL REFERENCE FRAME
}

\author{
IVAN I. MUELLER \\ Department of Geodetic Science and Surveying \\ The Ohio State University \\ Columbus, Ohio 43210-1247 USA
}

At the 20th General Assembly of the IUGG in Vienna, Austria, in August, 1991, Resolution No. 5 recommended that the concept of an International GPS Service for Geodynamics (IGS) be explored over the next several years and that campaigns be conducted to test the practicality of the concept.

The primary goals of the IGS are to provide the scientific community with high quality GPS orbits on a rapid basis, to provide earth rotation parameters of high resolution as a byproduct, to expand geographically the current International Terrestrial Reference Frame (ITRF) maintained by the International Earth Rotation Service (IERS), and to monitor the global deformations of the earth's crust.

The emphasis is on the word "service"; the above products are to be available on a regular and timely basis through the Central Bureau (currently at the Jet Propulsion Laboratory) and through the network centers (currently NASA's Crustal Dynamics Data Information System, the Institut Geographique National in Paris, and the Scripps Institute of Oceanography).

The Call for Proposals to participate in the 1992 test campaign (June 21 - September 23) was responded to by more than 100 organizations around the world and resulted in the setup of the first IGS structure consisting of the above-mentioned Bureau and network centers, seven data processing centers, and a core network of some 30 GPS observatories equipped with precise so-called P-code receivers and the just-as-important efficient data communication links to assure rapid data flow to the various data centers. More information on the early phase of IGS may be found in (Mueller, 1992; Mueller and Beutler, 1992).

The main purpose of the 1992 test campaign was to verify the participating organizations' ability to perform both with the observations including the rapid data flow as well as with the data analysis. In both respects the campaign must be considered a success, although as of this date it has not been completed. Preliminary scientific results include agreements in the orbits produced by the various processing centers at the submeter level after the removal of biases due to inconsistencies in the reference frames inherent in the calculations. The uncertainties of the corresponding daily coordinates of the pole range between $0.5-1.5$ mas.

Although the IGS is not approved yet as an international service, it appears to be certain that continuous GPS observations will greatly contribute to geodynamics of the future. In fact from October 1992 on GPS products will be introduced in the computations of the IERS and thus will have a beneficial effect on the future ITRF as well. It is hoped that eventually the IGS network will consist of several hundred stations which will then significantly expand the geographic coverage of the present ITRF.

\section{References}

Mueller, Ivan I., Permanent Satellite Tracking Networks for Geodesy and Geodynamics, G. L. Mader (ed.), Proc. IAG Symposium 109, Springer Verlag, 1992.

Mueller, Ivan I. and G. Beutler, The International GPS Service for Geodynamics-

Development and Current Structure, Proc. 6th Int. Geodetic Symp. on Satellite Positioning, Ohio State Univ., Columbus, 1992. 